or moon in bright clear weather, and extends with a radius of about three times the shadow's diameter around the head alone. It is probably due to diffraction of light-waves, an explanation of which at length may be read in Glazebrook's "Optics" and in other text-books. But your correspondent omits the most extraordinary character of the phenomenon. . It is a curious fact that any man can see the light around the shadow of his own head, but never about the shadow of another. Few people notice this halo, but when once pointed out to them, they tell me they frequently observe it. It is particularly clear when thrown across a valley from one ridge to another on the opposite side. I have puzzled over this spectral brightness for five years, and never found an explanation of the fact that no one can see anyone's halo but his own. I have delayed writing to NATURE until cause and effect could both be given, but they are not forthcoming.

Another curious appearance is a rainbow thrown by sunlight on black sound ice, probably due to polarization by crystals. On the one occasion when I saw it on a pond, I had no time to observe details. Has anyone seen the like? A. S. EvE.

Marlborough College.

\section{Nesting Habit of the House Sparrow.}

I SHOULD be glad to know if any of your correspondents have noticed a nesting habit of the house sparrow (Passer domesticus) which I have very frequently observed in this part of New Zealand. In many of the deep cuttings in our roads and in the cliffs upon our river-banks, where the formation is a light pumiceous sand, these birds are in the habit of burrowing holes similar to those of the sand-martin (Hirundo riparia). In some cases I have found these burrows by measurement to be as much as 6 feet in depth.

Can this be a recently acquired habit, and will it not have an influence upon the anatomical development of the bird ?

Waihou, Auckland, N.Z., September 5. G. L. Grant.

\section{Sonorous Sands.}

I Notice a letter from my friend Mr. A. R. Hunt in your issue of last week, and add a line to say that the sand which our common friend, the late Admiral Bedford, gave him was, probably, of my collecting.

I found that the sand in Studland Bay is sonorous, during a visit to Swanage, in 1869 , and was, for many years, in such constant communication with the late Admiral Bedford, exchanging notes and specimens, that $I$ think I must have given him the sonorous sand in question, though I cannot remember the circumstance.

Anyway, there is no doubt that the dry sands of Studland I3ay are powerfully sonorous. Walking with my son and a young friend of his across the bay in July 1869 , we all amused ourselves by licking the musical clust before us, the two younger pairs of hecls getting quite a volume of sound out of the performance.

Holmwoxd, Putney Hill, October 6.

\section{A Shell Collector's Difficulty.}

IF Mr. Layard will discard " tightly-corked tubes" altogether, and keep his minute shells in open-ended sections of glass tube, lightly closed, at top and bottom, with cotton-wool, he will have no more trouble from "milky efflorescence," which will not form in presence of the "thorough draft" he will thus establish in his cabinet.

Holmwood, Putney Hill, October 13.

D. PIDGEON.

Yorkshire Geological and Polytechnic Society.

Is accordance with a request made by the Council of the Yorkshire (ieological and Polytechnic Society, I am compiling a history of the past fifty years' work of the Society, and including in it biographical notices of some of its principal members. Amongst the latter was the Rev. W. Thorp, who for several years held the office of Honorary Secretary, and took great interest in the Society. He was at one time vicar of Womersley, and afterwards removed to Misson. Unfortunately I can obtain no records of his life. Can any of your readers assist me? Any information will he gratefully received and duly acknowledsed. I helicve Mr. Thorp died about I 857 .

Chevinedge, Ilalifax, October I5. JAMES W. DAvis.

\section{MODERN VIEWS OF ELECTRICITY. ${ }^{1}$}

\section{PART IV.--RADIATION.}

XI.

$W^{\mathrm{E}}$

E have next to consider what happens when electrical waves encounter an obstacle.

\section{Mochanism of Electric Radiation.}

In forming a mental image of an electrical wave, we have $t$, note that three distinct directions are involved. There is (I) the direction of propagation-the line of advance of the waves; (2) the direction of the electric displacements, at right angles to this; and (3) the direction of the magnetic axis, at right angles to each of the other two.

One may get a rough mechanical idea of the process of electrical radiation (at any rate in a plane) by means of the cog-wheel system already used in Part III. Imagine a series of elastic whee!s, in one plane, all geared together, and let one of them be made to twist to and fro on its axis ; from it, as centre, the disturbance will spread out in all directions, each wheel being made to oscillate similarly and to transmit its oscillation to the next. Looking at what is happening at a distance from the source, we shall see the pulses travelling from left to right; the electrical displacement, such as it is, being up and down; and the oscillating axes of the wheels being to and fro, or at right angles to the plane containing tise wheels. The electric displacement is small, because the positive and negative wheels gearing into one another move almost equally, and accordingly there is the merest temporary balance of one above the other, due to the elastic "give" of the wheels. The magnetic oscillations, on the other hand, are all in one sense, the positive wheels rotating one way and the negative the other: all act together, and so the magnetic oscillation is a more conspicuous fact than the electric oscillation. Hence it is often spoken of as electro-magnetic radiation rather than as electric radiation. But the energy of the electrostatic strain is just as great as that of the electro-magnetic motion; in fact the energy alternates from the potential to the kinetic form, or vice versit, at every quarter swing, just like every other case of vibration.

Prof. Fitzgerald, of Dublin, has devised a model of the ether, which by help of a little artificiality represents the two kinds of displacement-the electric and magneticvery simply and clearly.

$\mathrm{H}$ is wheels are separated from one another by a certain space, and are geared together by elastic bands. They thus turn all in one direction, and no mention need be made of positive and negative electricity as separate entities.

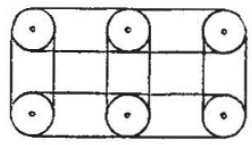

Fig. 48.-Fit zgerald's Fither Model. A set of brass wheels connected by co nmon elastic bands. If the hands are taken off any region, it becomes a perfect conductor, int, which disturbances cannot penetrate.

But, the wheels being massive, a rotatory disturbance given to one takes time to spread through the series, at a pace depending on the elasticity of the bands and the inertia of the wheels; and during the pcriod of acceleration one side of every elastic is stretched, while the other side is relaxed and therefore thickened. This thickening of the elastics goes on in one dirertion, and corresponds to an electric displacement in that direction; the direction being perpendicular both to the direction of alvance of the disturbance and to the axes of the wheels. A row of wheels corresponds to a section of a wave-front ; the ${ }^{1}$ Continued from p. $4 \mathrm{rg}$. 